\title{
OS CINCO MANDAMENTOS DO PROFESSOR DA EJA: AS IDENTIDADES E REPRESENTAÇÕES DO PROFESSOR DESEJÁVEL EM REPORTAGEM
}

\author{
Mônica Trindade Dias Magalbães* \\ Nádia Dolores Fernandes Biavati*
}

RESUMO: O presente artigo tem como objetivo apresentar uma análise da reportagem "Os cinco mandamentos do professor da EJA" publicada em 28 de março de 2019 no site da Revista Gestão Escolar da Nova Escola. Para desenvolvermos a análise, utilizamos como referencial teórico-metodológico a Teoria das Representações Sociais de Moscovici (2009), Jodelet (2011) e da Semântica da Enunciação, especificamente, Dias (2013) e Guimarães $(2017,2018)$ do qual adotamos e utilizamos a noção/conceito de locutor e enunciador. Também utilizamos o conceito de cultura proposto por Carmo (2014), de identidade propostos por Hall (2011), Coracini (2003) e Bauman (2005) e de diversidade cultural proposto por Cox (1993), com o intuito de identificar e analisar as representações sociais e as identidades que permeiam os discursos na reportagem. Percebemos que as representações de professor da EJA traçam o modo como o aluno deve ser considerado, para além dos conteúdos e habilidades a serem cobradas.

PALAVRAS-CHAVE: Cultura; EJA; Representação social; Semântica da enunciação.

\section{Introdução}

Diferentes programas educacionais, públicos e privados, já foram desenvolvidos com o intuito de levar educação a jovens e adultos que, por diversas razões, não tiveram acesso a ela em idade regular. Atualmente, um dos programas de educação de maior alcance para esse público é a Educação de Jovens e Adultos (EJA). De acordo com a Lei de Diretrizes e Bases da Educação Nacional (LDB, 2018), a EJA é uma modalidade de ensino que visa propiciar educação e aprendizagem àqueles que não puderam estudar e/ou dar prosseguimento aos estudos nos ensinos fundamental e médio na idade apropriada. Para cursar

\footnotetext{
* Mestranda em Discurso e Representação Social pela Universidade Federal de São João Del Rei (UFSJ).

${ }^{*}$ Doutora em Estudos Linguísticos pela Universidade Federal de Minas Gerais (UFMG). Professora adjunta da Universidade Federal de São João Del-Rei (UFSJ), onde atua no Programa de Mestrado em Letras: Teoria Literária e Crítica da Cultura.
} 
essa modalidade de ensino, os alunos do fundamental precisam ter idade superior a quinze anos e contar mais de dezoito anos, se estiverem no ensino médio.

Nessa empreitada, este trabalho analisa representações de professor, considerando os efeitos de sentido na reportagem" intitulada "Os cinco mandamentos do professor da EJA" por meio de uma análise visando compreender como as representações sociais e as identidades dos sujeitos-professores da EJA são construídas. A ideia é refletir sobre como a cultura pode influenciar na construção das representações sociais e identidades dos sujeitos-professores desta modalidade de ensino.

Metodologicamente, em um primeiro momento, apresentamos os conceitos e escolhas teóricas que sustentam o presente trabalho com o intuito de elucidar e fundamentar os nossos saberes sobre a teoria. Posteriormente, destacamos o objeto de estudo e como as representações perpassam os cinco mandamentos, com enfoque voltado para os saberes e práticas, visando identificar as identidades e o modo como se dão as representações dos sujeitos sociais - professores - envolvidos no modo de ser e atividades desejáveis da EJA apregoadas nos mandamentos.

O artigo está organizado, primeiramente, destacando os aspectos culturais que perpassam a realidade escolar, abordando o conceito de cultura estudado por Carmo (2014), de diversidade cultural apresentado por Cox (1993), de identidades por Coracini (2003), Hall (2011) e Bauman ( 2005) e de representações sociais apresentado por Moscovici (2009). Para a análise, usufruímos dos estudos da Semântica da Enunciação, voltando nosso olhar para a construção dos sentidos, destacando Dias (2013) e noções de locutor e enunciador estudadas por Guimarães $(2017,2018)$. Prosseguindo, realizamos uma análise dos relatos, presentes no corpus, uma reportagem de revista/ magazine cuja temática é a educação.

\footnotetext{
${ }^{1}$ Disponível em: https://gestaoescolar.org.br/conteudo/2147/os-cinco-mandamentos-do-professor-da-eja (em anexo). Acesso em: Nov.2019.
} 


\section{Revisão Teórica}

\section{A cultura e a diversidade cultural como forma de construção de identidade(s) e re- presentação(ões) sociais}

Sabemos que a sociedade é constituída de diversidade cultural, com crenças e hábitos vigentes. As práticas se estabelecem por meio das relações sociais e, desse modo, se firmam por meio dos discursos, escolhendo ou não valores e representações e identidades que se fortalecem ou são rejeitadas nas instituições como escola, família, igreja e Estado. As representações sociais e identidades envolvem as práticas culturais que influenciam o modo de ser/estar e viver e na construção e efetivação das relações sócio-históricos-culturais, viabilizando o modo econômico, ético, estético, e moral que acaba sendo mais aceito. Em virtude disso, vários autores, desde os primórdios, vêm discutindo e tentando chegar a um conceito que defina cultura.

$\mathrm{Na}$ tentativa de buscar um conceito de cultura que contribua para este trabalho, o qual visa analisar as representações sociais e a(s) identidade(s) dos professores da EJA que circulam em reportagem de revista/ magazine, visitamos Carmo (2014), no qual encontramos conceitos relevantes, pois traçam relações da cultura com os estudos da linguagem. Para o momento, destacamos: "cultura poderia significar a identidade de um povo ou de uma coletividade formada ao redor de elementos simbólicos compartilhados, inclusive os valores, gerando um primeiro entendimento em torno de noções como diferenças, identidades e lealdades" (CARMO, 2014, p. 28).

Concordamos com Carmo (2014), pois, a partir dos elementos simbólicos compartilhados, dos valores, das diferenças traçadas, controladas e respaldadas a partir das lealdades, as práticas sociais vão se consolidando sejam para validar a diferença e até mesmo a diversidade. Mas, por outro lado, essa validação pode acontecer de forma negativa como, por exemplo, a exclusão e o preconceito. E, relacionando tudo isso ao contexto escolar da EJA, podemos complementar com outro conceito de cultura de Carmo (2014), que nos diz que

em outro sentido, cultura seria os hábitos e costumes que representam e podem identificar um modo de ser de um povo, noção que traz em si os costumes como singulares específicos. Cultura seria 
então o todo comportamental (emocional e intelectual) de um povo ou, às vezes, de uma coletividade. (CARMO, 2014, p. 28)

Assim, o modo de ser e de ver pode partir desse todo comportamental, caracterizando a cultura escolar, por exemplo. Desse modo, podemos dizer que professor e aluno seguem formas de ser e de ver o mundo e a sociedade na instituição escolar, traçando e seguindo traços definidos a partir da ética, dos hábitos e da rede de valores e de comportamentos desejados.

Nesse sentido, percebemos que o espaço escolar, neste trabalho, mais especificamente, o da EJA, é um local que se constitui pela gama de diversidade cultural, seja considerando o tempo, a trajetória, a faixa etária, os preconceitos, os traços de exclusão, dentre outros pontos que derivam dos espaços e valores dos grupos culturalmente diferentes que ali frequentam ou trabalham. Diante disso, concordamos com Cox (1993) que acredita que a diversidade está relacionada à cultura, por isso a adjetiva como cultural, e a define da seguinte maneira: "diversidade cultural diz respeito à representação em um sistema social, de pessoas com afiliações a grupos claramente diferentes em termos de significado cultural" (COX ,1993, p. 6).

Assim sendo, podemos compreender que, de acordo com Cox (1993), a diversidade cultural está ligada à construção da representação das pessoas que fazem parte de um sistema social com adesões diversificadas. Isso significa que um grupo pode ser observado como diferente do outro em uma sociedade específica. Assim, diante das vivências, diferenças e diversidades culturais dos professores encontradas na modalidade de ensino EJA, bem como diante dos relatos da reportagem em análise comungamos com Cox (1993), que afirma que "as diferenças entre os indivíduos ocorrem a partir das vantagens econômicas e de poder que uns obtiveram em relação aos outros no decorrer da história” (COX,1993, p. 6). Isso, portanto, confirma que as representações dos professores da EJA são construídas pelas suas individualidades e vivências, aspectos que de certo modo seguem um consenso e se relacionam à noção de identidade, próximo tópico a ser discutido. 


\section{A(s) identidade(s) na perspectiva de Hall, Coracini e Bauman}

Diante dessa perspectiva, acreditamos que o sujeito-professor não possui uma identidade, mas sim carrega vários traços, de identidades que são construídas pelos discursos que se dão em efeitos de sentido, pelas fragmentações, pelas vivências. E, visitando Hall (2011), nos deparamos justamente com essa concepção, pois, rememoramos o seguinte trecho da produção do autor:

um sujeito, previamente vivido, com uma identidade unificada e estável, está se tornando fragmentado; composto não de uma única, mas de várias identidades, algumas vezes contraditórias ou não resolvidas. Esse processo produz o sujeito pós-moderno, conceptualizado como não tendo uma identidade fixa, essencial ou permanente. A identidade torna-se uma "celebração móvel": formada e transformada continuamente em relação às formas pelas quais somos representados nos sistemas culturais que nos rodeiam. (HALL, 2011, p. 12)

Logo, podemos inferir que essa fragmentação também atinge o sujeito-professor da EJA, ainda que se permita delinear um perfil constituído de "mandamentos" para esse profissional. Tal fato fomenta a construção de identidades e representações, de acordo com experiências que visualizam formas de ser/estar na profissão. Corroboramos isso consultando Coracini (2003), uma vez que ela é um expoente sobre o estudo das identidades no campo educacional. E nas palavras da autora,

as representações que habitam o imaginário seja do aluno, seja do professor são reveladoras da identidade de um e de outro, se compreendermos identidade não como um conjunto de características congeladas que nos diferenciam uns dos outros, mas como um processo que não acaba nunca, que está o tempo todo se modificando e que constitui a complexidade do sujeito. Sabemos também que toda representação se constrói a partir das experiências pessoais, mas não apenas: elas se constroem a partir das experiências dos outros, daqueles que nos cercam e que nos levam a crer nisto ou naquilo, que nos dizem quem somos. (CORACINI, 2003, p. 219)

Portanto, quando tratamos dos conhecimentos que cercam o tema e quando lemos a reportagem "Os cinco mandamentos do professor da EJA", podemos observar que a identidade emerge tanto do imaginário da entrevista quanto das experiências pessoais 
quanto aquelas obtidas pela alteridade contribuem para a formação das representações e das identidades desses sujeitos.

E para corroborar a questão da construção da(s) identidade(s) como não congelada e inacabada, o sociólogo Bauman (2005) nos alerta,

tornamo-nos conscientes de que o "pertencimento" e a "identidade" não têm a solidez de uma rocha, não são garantidos para toda a vida, são bastante negociáveis e renegociáveis, e de que as decisões que o próprio individuo toma, os caminhos que percorre, a maneira como age - e a determinação de se manter firme a tudo isso - são fatores cruciais tanto para o "pertencimento" quanto para a "identidade". (BAUMAN, 2005, p. 17)

Logo, as identidades são construídas de acordo com os caminhos e decisões tomadas pelos sujeitos que se relacionam, se representam e representam o outro nas tomadas de decisões.

\section{Um olhar sobre a(s) representação(ões) social(is): Moscovici e Jodelet}

Tratamos do que Serge Moscovici (2009), assim como Jodelet (2011), tomam como o olhar da Psicologia Social, destacando noções importantes sobre representações e práticas, uma vez que são elas que são constitutivas, por exemplo, do como ser/estar/ agir em uma profissão. Para esses autores, as representações sociais mostram que as impressões simbólicas da realidade expõem os saberes e as vivências dos sujeitos, carregando discursos sobre a realidade, sobre as identidades, os hábitos, os costumes e sobre a cultura, resultando em uma nova maneira de viver, em posicionamentos de/ sobre uma identidade consensual. Portanto,

[...] precisamos saber como nos comportar, dominá-lo (o mundo) física ou intelectualmente, identificar e resolver os problemas que se apresentam: é por isso que criamos representações. Frente a esse mundo de objetos, pessoas e acontecimentos ou ideias, não somos (apenas) automatismos, nem estamos isolados num vazio social: partilhamos esse mundo com os outros, que nos serve de apoio, às vezes de forma convergente, outras pelo conflito, para compreendêlo, administrá-lo ou enfrentá-lo. Eis por que as representações sociais são tão importantes na vida cotidiana. Elas nos guiam no modo 
de nomear e definir conjuntamente os diferentes aspectos da realidade diária, no modo de interpretar aspectos, tomar decisões e, eventualmente, posicionar-se frente a eles de forma defensiva. (JODELET, 2011, p. 61)

Consequentemente, conforme a pesquisadora, a construção das representações se dá na vida cotidiana, ou seja, nas interações e práticas sociais. Já Moscovici (2009) nos dá uma informação importante de que é através da linguagem que os sujeitos se constroem e são construídos em relação aos outros. Para o autor, a representação social se dá como manifestação construída nas interações. É a linguagem que nos dá meios de perceber como, por exemplo, a escola cria, propaga ou inda dissemina as representações. Moscovici (2009) esclarece que

a própria linguagem, quando ela carrega representações, localiza-se a meio caminho entre o que é chamado de linguagem de observação e a linguagem da lógica; a primeira, expressando puros fatos - se tais fatos existem - e a segunda, expressando símbolos abstratos. Este é talvez, um dos mais marcantes fenômenos do nosso tempo - a união da linguagem e da representação. (MOSCOVICI, 2009, p. 26)

Moscovici (2009) ainda complementa dizendo que "as representações sociais devem ser vistas como uma maneira de compreender e comunicar o que nós já sabemos. Elas [...] têm como objetivo abstrair sentido do mundo e introduzir nele ordem e percepções, que reproduzam o mundo de forma significativa" (MOSCOVICI, 2009, p. 46). Dessa forma, sempre utilizamos algo concreto, no caso a linguagem, como forma de contato com o mundo para construir um conhecimento abstrato.

Nessa perspectiva, Moscovici (2009) nos apresenta em sua teoria das representações sociais dois processos que abordam o concreto e o abstrato, aspectos que auxiliam na construção das relações sociais. São eles: ancoragem e objetivação. O autor afirma que

Ancoragem e objetivação são, pois, maneiras de lidar com a memória. A primeira mantém a memória em movimento e a memória é dirigida para dentro, está sempre colocando e tirando objetos, pessoas e acontecimentos, que ela classifica de acordo com um tipo e os rotula com um nome. A segunda, sendo mais ou menos direcionada para fora (para outros), tira daí conceitos e imagens para juntálos e reproduzi-los no mundo exterior, para fazer as coisas conhecidas a partir do que já é conhecido. (MOSCOVICI, 2009, p. 78) 
Portanto, de acordo com o autor, a ancoragem é um processo pelo qual as coisas são nomeadas e classificadas resultando na sua existência ou fazendo-as com que sejam percebidas no mundo. Já a objetivação é o processo pelo qual algo abstrato é transformado em algo quase concreto. Ou seja, é transferir o que está no pensamento em algo que possa ter existência no mundo. Acreditamos que esses dois processos nos ajudam na elaboração de aspectos que marcam o que compreendemos como características e "mandamentos" para o professor tornar-se, por exemplo, um bom professor da EJA, conforme o instituído na reportagem. Dessa forma, podemos dizer que, por meio da linguagem, resgatamos os processos de ancoragem e objetivação, repercutindo na(s) construção(ões) das representação(ões) social(ais) que circulam sobre a escola e a relação que cabe ser percebida da escola e o modo como a rede de comportamentos delineia o professor da EJA.

Assim sendo, em consonância com Moscovici (2009), ressaltamos que: “a) as representações sociais devem ser vistas como uma "atmosfera", em relação ao indivíduo ou ao grupo; b) as representações são, sob certos aspectos, específicas de nossa sociedade" (MOSCOVICI, 2009, p. 53). O olhar para as representações, ao nosso ver, requer a observação da linguagem e, pelos discursos, valores são situados na rede de comportamentos desejáveis expressos na rede de sentidos divulgados sobre como agir como professor da EJA, ao que tudo indica, desvencilhado da simples cobrança do volume de conteúdos a serem apreendidos, conforme a dinâmica da escola atual, em muito apoiada em documentos como a Base Nacional Comum Curricular.

Observando a reportagem em lupa, resgatamos conhecimentos da Semântica da Enunciação, que abordamos a seguir.

\section{Construindo um percurso para o olhar às representações}

A Semântica da Enunciação estuda a significação da linguagem, tendo como unidade de análise o enunciado e a construção das relações entre forma e sentido. Várias ideias de autores reconhecidos contribuíram para a base e desenvolvimento dessa teoria, como, 
por exemplo, Oswald Ducrot e Émile Benveniste. No Brasil, temos estudos de Eduardo Guimarães, Luiz Francisco Dias, dentre outros pesquisadores.

Ao utilizarmos a teoria da Enunciação, devemos, primeiramente, ter em mente o que significa o termo enunciação e como tomamos a enunciação para compreender o modo como os mandamentos se dão em textos. Nos termos de Dias (2013), a

enunciação é o acontecimento de produção do enunciado, o qual adquire sentido na medida em que uma mesma atualidade motivadora da formulação adquire pertinência na relação com outras enunciações, concebidas como traços da memória discursiva. (DIAS, 2013, p. 15)

Assim sendo, a enunciação e, também, o acontecimento enunciativo estão relacionados ao funcionamento da língua na produção dos discursos, se considerarmos os sentidos $\mathrm{e}(\mathrm{m})$ enunciados.

Neste trabalho, utilizamos, em nossas análises, como arcabouço teórico-metodológico a configuração da cena enunciativa proposta por Guimarães (2017; 2018). Antes de mostrarmos tal configuração, apresentamos o conceito de espaço de enunciação, bem como o de político, os quais estão diretamente interligados à cena enunciativa.

Nos espaços de enunciação há uma divisão social e política da língua. Tendo o político, ou seja, divisão social da língua como a base para o desenvolvimento das relações sociais. Para Guimarães, os falantes são os seres de linguagem que são construídos ao se relacionarem com as línguas em escolhas que se dão a partir do modo de ver o mundo. Em vista disso, Guimarães (2018) descreve o espaço de enunciação:

os falantes não são os indivíduos, as pessoas que falam esta ou aquela língua. Os falantes são estas pessoas enquanto determinadas pelas línguas que falam. Neste sentido, falantes não são as pessoas na atividade físico-fisiológica, ou psíquica de falar. São sujeitos da língua enquanto constituídos por este espaço de línguas e falantes que chamo espaço de enunciação. (GUIMARÃES, 2017, p. 24)

Apresentamos a noção de cena enunciativa para a Semântica da Enunciação para toma-la como recurso para considerar as perspectivas do corpus. Nas palavras de Guimarães (2017, p. 31, grifos do autor), "uma cena enunciativa se caracteriza por constituir modos 
específicos de acesso à palavra dadas as relações entre as figuras da enunciação e as formas linguísticas”. Ainda, Conforme Guimarães (2018, p. 58), “a enunciação é politópica, a cena enunciativa se configura por uma divisão de lugares de enunciação". Portanto, a cena é composta por "aquele que fala" e "aquele para quem se fala", isso é, pelas figuras da enunciação (GUIMARÃES, 2017, 2018).

Diante isso, descrevemos o modo de funcionamento do dizer que apresenta os papéis assumidos pelas figuras da enunciação no agenciamento enunciativo. Conforme Guimarães $(2017,2018)$, o falante, ao assumir o papel de enunciador, se desdobra em lugar que diz (Locutor/ L); lugar social do dizer (alocutor/ al-x) e lugar de dizer (enunciador (E): individual, coletivo, genérico e universal). Tais papeis são evidenciados a seguir.

\section{Observando a Cena Enunciativa para compreender as representações sociais: um caminho de análise}

Tomamos para análise a reportagem intitulada "Os cinco mandamentos do professor da EJA" de autoria de Ewerton Souza, cujo referencial histórico o situa como identidade envolvida com a EJA, uma vez que ele é descrito como coordenador geral no Centro de Integração de Educação de Jovens e Adultos (CIEJA) Clóvis Caitano Miquelazzo, escola da prefeitura de São Paulo, e que lida exclusivamente com a Educação de Jovens e Adultos, especialmente, na faixa etária dos 15 aos 18 anos. Foi um dos 50 finalistas do Prêmio Educador Nota 10 de 2017. Essa reportagem foi publicada em 28 de março de dois mil e dezenove na sessão "Educação de Jovens e Adultos" pela Gestão Escolar, que faz parte do grupo da Revista Nova Escola, uma revista brasileira impressa e virtual. A reportagem relata as experiências, trajetórias e vivências dos professores. Diante disso, podemos complementar que esta interação influencia nas relações e interações sociais e, consequentemente, nas práticas sociais assim como na diversidade.

De acordo com a configuração da cena enunciativa da reportagem, apresentaremos, agora, as figuras da enunciação. O Locutor, ou seja, aquele que assume o lugar que diz, que nas palavras de Guimarães (2017, p. 31-32) “é [...] o lugar que se representa no próprio 
dizer como fonte deste dizer", é Ewerton Fernandes de Souza, que tem como o seu correlato, isto é, como Locutário, os sujeitos interessados na EJA. Quanto ao lugar social do dizer, temos a presença do alocutor-coordenador geral no CIEJA Clóvis Caitano Miquelazzo, que possui como principal correlato o alocutário-professor, que "é aquele para quem o alocutor diz o que se diz numa alocução" (GUIMARÃES, 2018, p. 56). Dessa forma, por meio dessas figuras da enunciação encontramos os enunciadores que assumem o lugar de dizer, os quais analisaremos a seguir.

Começando pelo enunciador-individual, que de acordo com do Silveira (2019), é aquele que se identifica como o lugar de dizer assumindo o eu enunciativo. Podemos observá-lo nos excertos (1), (2) e (3), a seguir.

(1) "[...] Como "minha" formação inicial era em Letras, "minha” cabeça - e "meus" planos estavam cheios de macetes de ortografia, regras de regência e concordância, princípios de bem escrever. Que tola arrogância! O que encontrei na sala de aula foi outra língua. A fala de "meus" alunos trazia anos de experiências e uma diversidade de trajetórias que um plano de ensino formatado previamente jamais daria conta".

(2) "O princípio que havia aparecido em "minha" conversa inicial com a professora é o de que a aprendizagem é dialógica, ou seja: eu, educador, não somente ensino, mas também aprendo com as outras pessoas".

(3) "Todos estão ali, fisicamente juntos no mesmo espaço e "minha" postura e prática em sala de aula deve dialogar com todos".

Em (1), (2) e (3), o alocutor-coordenador da CIEJA mobiliza um enunciador-individual a partir do uso dos pronomes possessivos "minha" e "meus", portanto, associa o dizer à representação de si e das próprias práticas, no caso, ao professor/coordenador Ewerton Fernandes de Souza, que se situa como quem apresenta as próprias experiências e seus valores, como atenção à própria visão do objeto de ensino, da própria postura e dos valores. Assim sendo, podemos dizer que em (1), (2) e (3) a figura enunciativa do coordenador entrevistado constrói a representação de um professor que precisa entender as trajetórias dos seus alunos e o que ele tem ancorado em sua mente (abstrato) seja transformado em algo concreto para que possibilite aos alunos apreender de acordo com suas vi- 
vências, trajetórias e diversidades de forma dialógica. A partir dessa representação, verificamos que a identidade se dá pela alteridade, da convivência com os alunos e compreensão de que a aula é dialógica e que educador e educando aprendem juntos, possibilitando-nos a acreditar que a identidade de um professor deve propiciar que o aluno tenha vez e voz.

Outro enunciador encontrado no corpus é o enunciador-coletivo, ou seja, o enunciador "ligado a um lugar, diríamos, corporativo, de um conjunto, que o dizer apresenta como um todo específico" (GUIMARÃES, 2013, p. 193), que por vezes se manifesta como o nós (professores) e eles (alunos). E isso pode ser identificado, como, por exemplo, em palavras que demonstram uma coletividade (professor de Jovens e Adultos, por exemplo) etc. Podemos observar o que acabamos de mencionar nos próximos excertos (4), (5) e (6).

(4) "Aprendi a duras penas naquele ano como ser um professor para jovens e adultos. Essa aprendizagem me fez descobrir na prática aquela máxima apregoada pelo mestre Paulo Freire: "Ninguém ignora tudo. Ninguém sabe tudo. Todos "nós sabemos" alguma coisa. Todos "nós ignoramos" alguma coisa, por isso "aprendemos" sempre".

(5) "Não "podemos" jamais nos esquecer de que cada educando tem seu tempo. No caso de jovens e adultos, isso é importantíssimo! Achar que todos aprenderão do mesmo modo ou no mesmo tempo levará ao desânimo daqueles que, por este ou aquele motivo, não conseguem acompanhar a turma. Não significa que "esperaremos" todos chegarem ao mesmo ponto, o que é igualmente um desastre. Significa sim que "vamos" estabelecer em "nossa" aula, plano, projeto, objetivos para que cada qual avance dentro de suas potencialidades e de acordo com o seu momento".

(6) "Daí que a postura do professor de EJA não deve negligenciar nunca o fato de que "somos" adultos lidando com jovens ou adultos. Como já disse, este princípio da relação deve estar presente em "nossas" conversas, mas também no material que "levamos" para a sala de aula. Temas, leituras, exercícios devem ilustrar e dialogar com o mundo que eles efetivamente vivem. Daí o cuidado que "devemos" ter com materiais que sejam trazidos das turmas regulares".

Em (4), (5) e (6), o alocutor-coordenador pronuncia os pronomes "nós" e "nossa(s)" e os verbos conjugados nas pessoas do plural "sabemos, ignoramos, aprendemos, podemos, esperamos, vamos, somos, levamos e devemos" o que nos leva a inferir que ele já não assume mais somente a figura enunciativa do coordenador, e sim à de uma coletividade. Logo, nesses enunciados, há o agenciamento do alocutor-coordenador por meio da transferência do "eu" para o "nós e nossa". Nesses enunciados, o enunciadorcoletivo evoca que todos os professores devem entender que ninguém sabe tudo. Ou seja, 
que tanto professor quanto aluno estão em constante aprendizado. Além disso, ele ressalta que cada aluno tem o seu tempo de apreender e que cabe ao professor, principalmente de jovens e adultos, viabilizar processos de didatização que propiciem esses alunos a caminharem juntos a partir de suas vivências e diálogos de forma que eles não sejam prejudicados.

Nesse sentido, os excertos (4), (5) e (6) destacam a representação de professores que estão preocupados em entender as particularidades de cada aluno assim como o seu cotidiano na perspectiva de impulsioná-los e de valorizar as suas qualidades e potencialidades. Dessa forma, podemos atribuir a eles a identidade de pessoas que estão preocupadas com a educação, e, principalmente, com a educação na modalidade EJA. Que possuem, assim, o intuito de não deixar com que esses educandos desistam mais uma vez da escola por causa de dificuldades, sejam elas educacionais ou sócio histórica e econômicas.

Por enunciador-universal, entendemos que é aquele que nos mostra uma verdade partilhada, aquele que mostra o Locutor fora da história criando o julgamento de verdadeiro ou falso. É isso que verificaremos em (7):

(7) "Respeitar o tempo, a trajetória e a faixa etária dos alunos são essenciais para lidar com todos os alunos, mas, especialmente, com aqueles que retornam à escola na vida adulta".

Pela afirmação colocada, o enunciador-universal expõe verdades que não propiciam discussões. Isto é, são verdades tidas como absolutas pela sociedade. Elas fazem parte de um consenso de que professor e aluno aprendem juntos e que o respeito do professor para com o aluno é essencial. Essa forma de enunciador-universal nos permite mencionar que através das verdades postas é construída a representação de um professor que respeita as peculiaridades e que aprende junto com o aluno. E, com isso, constitui a identidade de respeito, compreensão e de troca entre professor e aluno na perspectiva de que devemos sempre ouvir o outro para que a re(construção) do conhecimento aconteça.

Percebe-se pelo olhar enunciativo que a construção enunciativa se dá a todo momento para representar o olhar que pretende "preparar" o leitor para tomar contato com as peculiaridades da EJA. Desse modo, a representação de professor condiz com a construção de valores que seguirão essas características e práticas de educador ao lidar com essa 
forma de ensino. Nessa direção, cada item da reportagem ressalta e comenta cada "mandamento" ao professor, valorizando um olhar voltado para o aluno que frequenta essa modalidade de ensino. Seguem os seguintes mandamentos comentados pelo locutor/enunciador ao longo da reportagem:

1- Levarás em conta a trajetória do aluno

2- Respeitarás o tempo de cada um

3- Reconhecerás cada faixa etária com suas especificidades

4- Respeitarás a diversidade como regra.

5- Motivarás sempre e não desistirás jamais.

$\mathrm{Na}$ reportagem, os referidos mandamentos são traçados em subtítulos de seção, utilizando a segunda pessoa, em associação intertextual aos mandamentos bíblicos. De maneira sintética, o enunciador se coloca aos moldes de um enunciador universal, para decretar e comentar as representações de professor de EJA legitimadas diante do quadro ora posto. Isso significa que cada professor da EJA, aos olhos do entrevistado, referenda práticas que coadunam com o olhar à diversidade e respeito às especificidades do público da EJA. A identidade delineada de professor é enunciada para indicar valores e costumes desejáveis que exploram o aspecto humano de cada aluno, em detrimento da rede de conteúdos a ser ministrada. Essa dimensão acaba por traçar e respeitar a diversidade cultural apregoada para a instituição escolar no cotidiano atual, com peculiaridades que derivam da dimensão escolar da EJA.

\section{Considerações finais}

Neste artigo, analisamos a reportagem "Os cinco mandamentos do professor da EJA", traçando representação(ões) social(is) e a(s) identidade(s) do professor da EJA através das Teoria das Representações Sociais de Moscovici (2009) e Jodelet (2011). Trabalhamos com noções da Semântica da Enunciação Dias (2013) e Guimarães $(2017,2018)$ e o conceito de cultura proposto por Carmo (2014), de identidade propostos por Hall (2011), Coracini (2003) e Bauman (2005) e de diversidade cultura proposto por Cox (1993).

Acreditamos que a(s) representação(ões) social(is) e a(s) identidade(s) são processos que fazem parte da construção das práticas e das relações sociais e que elas estão ligadas à 
determinada cultura, hábitos e costumes. Para que essa construção aconteça, elas precisam de um sujeito ou um grupo social para serem constituídas a partir do contexto sócio-histórico-cultural.

Diante disso, os efeitos de sentido inferidos a partir da análise das figuras enunciativas presentes na cena enunciativa por meio da materialidade linguística, assim como a Teoria das Representações Sociais e identidades utilizadas neste artigo, a análise nos propiciou os seguintes resultados após a análise da reportagem em questão: a representação de professor é traçada a partir dos elementos que valorizam as especificidades dos professores da EJA, considerando as variáveis do tempo e adesão individual ao projeto de ensino pelos alunos. Os locutores e enunciadores percebidos na análise reivindicam que o professor da EJA seja atento à trajetória, à faixa etária e o cotidiano dos alunos jovens e adultos. Isso porque, devido a sua condição, o aluno necessita de um apoio maior para que não fique desmotivado e não desista novamente dos estudos, tendo em vista a identidade do aluno da EJA que, por algum motivo, não teve a oportunidade de estudar no tempo adequado.

Nesse sentido, encontramos diferentes representações sociais e identidades desejáveis, como por exemplo, a representação de um professor compreensivo e com identidade dialógica; representação e identidade de um professor preocupado com a educação e trajetórias dos alunos; representação e identidade de respeito ao tempo e necessidades desse aluno e, por fim, a representação e identidade de que ninguém sabe tudo, ou seja, que estamos em permanente construção, aspectos tratados nas seções que trouxeram a explicação de cada mandamento.

Logo, ao mesmo tempo que a escola convencional valoriza o ensino- aprendizagem traçado a partir das práticas que conduzem a parâmetros e bases comuns de conteúdos e habilidades, podemos dizer que professor da EJA é interpelado a debruçar o seu olhar sobre os alunos jovens e adultos devido às suas trajetórias e vivências, buscando sempre ensinar a partir do contexto de mundo dos alunos, visando a observar a diversidade cultural e as potencialidades de cada um. 


\title{
THE FIVE COMMANDMENTS TO YOUNG AND ADULT EDUCATION TEACHERS: IDENTITIES AND REPRESENTATIONS OF THE DESIRED TEACHER IN A NEWSPAPER REPORT
}

\begin{abstract}
The present work makes an analysis of a newspaper report entitled 'The five commandments to the young and adult education teachers', published on March 28th 2019 on the website of the magazine 'Gestão Escolar (Nova Escola)'. The analysis was based on the theoretical and methodological frameworks of Social Representation Theory, by Moscovici (2009) and Jodelet (2011) and Enunciation Semantics Theory, by Dias (2013) and Guimarães (2017, 2018), whose concept of speaker and enunciator were adopted in this paper. The concepts of culture, proposed by Carmo (2014); identity, proposed by Hall (2011), Coracini (2003) and Bauman (2005); and cultural diversity, proposed by Cox (1993), were also used in order to identify and analyze the social representations and identities that permeate the discourses in the newspaper report. The conclusion is that the representations of young and adult education teachers outline how the student should be regarded, beyond the contents and skills demanded from them.
\end{abstract}

KEYWORDS: Culture; EJA; Social representation; Semantics of enunciation.

\section{REFERÊNCIAS}

BAUMAN, Zygmunt. Identidade: entrevista a Benedetto Vecchi. Rio de Janeiro: Zahar, 2005.

BRASIL. Lei 13632 - março 2018. Lei de Diretrizes e Bases da Educação Nacional. Brasília: Ministério da Educação, artigos 37 e 38, 2018.

CARMO, Cláudio Márcio do. O lugar da cultura nas teorias de base linguística sistêmico funcional: multimodalidade e produção de sentido na dança-ritual de Oxóssi. Curitiba: Appris, 2014.

CORACINI, Maria José. A celebração do outro. In: CORACINI, Maria José. (Org.). Identidade \& discurso: (des)construindo subjetividades. Campinas, SP: Editora da UNICAMP; Chapecó: Argos, 2003. p. 197-221.

COX, Taylor. Cultural Diversity in Organizations: theory, research \& practice. San Francisco: Berrett-Koehlerpublishers,p. 6, 1993.

DIAS, Luiz Francisco. Formações nominais designativas da língua do Brasil: uma abordagem enunciativa. Letras, Santa Maria, v. 23, n. 46, p. 11-22, jan./jun. 2013.

GUIMARÃES, Eduardo. Ler um texto uma perspectiva enunciativa. Revista da ABRALIN, v.12, n.2, p. 189- 205, jul./dez. 2013.

GUIMARÃES, Eduardo. (2002). Semântica do acontecimento. Campinas: Pontes, 4. ed., 2017.

GUIMARÃES, Eduardo. Semântica enunciação e sentido. Campinas: Pontes, 2018.

HALL, Stuart. A identidade cultural na pós-modernidade. 11. ed. Rio de Janeiro: DP\&A, 2011. 
JODELET, Denise. Representações Sociais: um domínio em expansão. In: JODELET, D. (Org.). As representações sociais. Rio de Janeiro: UERJ, 2011.

MOSCOVICI, Serge. Representações sociais: investigações em psicologia social. 6. ed. Petrópolis, RJ: Vozes, 2009.

SILVEIRA, Edna Cristina. A nomeação de programas sociais: um olhar semântico enunciativo. UFSJ, Dissertação de mestrado, 2019, 155p.

Recebido em: 29/04/2020.

Aprovado em: 20/05/2020. 